\title{
Socioeconomic inequalities in the use of outpatient services in Brazil according to health care need: evidence from the World Health Survey
}

\author{
Célia L Szwarcwald*, Paulo RB Souza-Júnior, Giseli N Damacena
}

\begin{abstract}
Background: The Brazilian health system is founded on the principle of equity, meaning provision of equal care for equal needs. However, little is known about the impact of health policies in narrowing socioeconomic health inequalities. Using data from the Brazilian World Health Survey, this paper addresses socioeconomic inequalities in the use of outpatient services according to intensity of need.

Methods: A three-stage cluster sampling was used to select 5000 adults (18 years and over). The non-response rate was $24.7 \%$ and calibration of the natural expansion factors was necessary to obtain the demographic structure of the Brazilian population. Utilization was established by use of outpatient services in the 12 months prior to the interview. Socioeconomic inequalities were analyzed by logistic regression models using years of schooling and private health insurance as independent variables, and controlling by age and sex. Effects of the socioeconomic variables on health services utilization were further analyzed according to self-rated health (good, fair and poor), considered as an indicator of intensity of health care need.

Results: Among the 5000 respondents, $63.4 \%$ used an outpatient service in the year preceding the survey. The association of health services utilization and self-rated health was significant $(p<0.001)$. Regarding socioeconomic inequalities, the less educated used health services less frequently, despite presenting worse health conditions. Highly significant effects were found for both socioeconomic variables, years of schooling $(p<0.001)$ and private health insurance $(p<0.00)$, after controlling for age and sex. Stratifying by self-rated health, the effects of both socioeconomic variables were significant among those with good health status, but not statistically significant among those with poor self-rated health.

Conclusions: The analysis showed that the social gradient in outpatient services utilization decreases as the need is more intense. Among individuals with good self-rated health, possible explanations for the inequality are the lower use of preventive services and unequal supply of health services among the socially disadvantaged groups, or excessive use of health services by the wealthy. On the other hand, our results indicate an adequate performance of the Brazilian health system in narrowing socioeconomic inequalities in health in the most serious situations of need.
\end{abstract}

\section{Background}

The main purpose of health system performance assessment is to provide decision makers with reliable evidence for policy and decision making. It is an essential step to guarantee quality of care and to make decisions that satisfy the population needs and expectations [1].

\footnotetext{
* Correspondence: celials@icict.fiocruz.br

Fundação Oswaldo Cruz, Rio de Janeiro, Brasil
}

The increasing evidence of the association between health and socioeconomic status from studies conducted throughout the world [2-4], using either individual characteristics such as education, income or ethnicity [5-8] or group characteristics to explain social and spatial variations in health $[9,10]$, has promoted the monitoring of socioeconomic health inequalities as an important component of a health system performance assessment $[11,12]$. Actions and programs are evaluated based on their performance in diminishing the socioeconomic

(c) 2010 Szwarcwald et al; licensee BioMed Central Ltd. This is an Open Access article distributed under the terms of the Creative 
gradient $[13,14]$, including the contribution of primary care $[15,16]$.

In some countries, reducing inequalities in health has been identified as a key target in the context of government policies and strategic programs [17-21]. A research agenda to guide efforts for better understanding of interventions that promote equity has been proposed $[15,22]$. Over the last twenty years, this issue has been emphasized in the policy agenda of the World Health Organization (WHO), and has been considered as one of its first priorities [23-25].

The main argument for the reduction in health inequalities is based on the equity principle, which incorporates the dimension of social justice [26,27]. Nevertheless, even though the goal of health inequality reduction is founded on principles of social justice, a step forward is necessary to transpose these principles in concrete actions targeting inequality reduction. In practical terms, assessing health inequity within a society requires not only examining inequalities in health between more and less socially affluent groups, focusing on those inequalities likely to be avoidable [28], but also on specific actions known to effectively benefit the poorest [29].

Founded on the principle of equity, the Brazilian health system (SUS) provides universal access and comprehensive care, meaning equal provision of care for equal needs [30]. However, little is known about the impact of health policies in narrowing socioeconomic health inequalities.

As part of the World Health Organization (WHO) project focused on health systems performance assessment of the member countries [31], the World Health Survey (WHS) was carried out in Brazil in 2003. Using data from the Brazilian survey, this paper addresses the socioeconomic inequality in utilization of health services and its relationship with self-perception of health, as an indicator of need.

\section{Methods}

The World Health Survey (WHS) was carried out in Brazil in 2003. The research was approved by the Research Ethics Committee of the Fundação Oswaldo Cruz - FIOCRUZ. Coordination of the survey and fieldwork as well as selection, training and supervision of interviewers were in charge of FIOCRUZ. The interviewers were undergraduate students or professionals from the health sector.

The survey population corresponded to the entire set of permanent private households in Brazil, except for those located in the rural areas of the Northern macroregion and special census tracts (military barracks and bases, lodgings, camps, ships/vessels, prisons, nursing homes, orphanages, convents/monasteries, and hospitals). According to this definition, the sample population included 207,513 tracts $(96.2 \%$ of the 215,811 census tracts from 2000). According to the 2000 Population Census, of the 45,053,286 permanent private households existing in Brazil, 44,005,362 (97.7\%) were covered by the sample population.

To ensure that the sample was representative of the urban and rural areas of the small, medium, and large municipalities, which have important differences in the size and type of health services, the tracts were divided into six strata based on urban/rural area and the municipality population size $(<50,000$ inhabitants; 50,000399,999; and 400,000 +).

A three-stage cluster sampling was used to select 5000 adults (18 years and over). In the first stage, 250 census tracts were systematically selected, with probability proportional to size. Within each stratum, the tracts were ordered (before their selection) according to mean income (implicit stratification), which guaranteed the representation of all the socioeconomic levels in each stratum. In the second stage, households were randomly selected using an inverse sample design to assure 20 interviews by sector [32]. In each household, one adult (18 years and over) was randomly selected to answer a face-to-face interview and one household member was identified to respond to questions relative to household characteristics, assets and expenditures. The random selection method proposed by the WHO consisted of using Kish numbers (numbers selected with equal probability from the sets of natural numbers with 2, 3, 4, 5, or 6 elements), which was adapted in the Brazilian survey for households with up to 12 adult residents [32].

In all 250 sample tracts, all 20 planned interviews were obtained, and an average of 34.4 households visits were made. The mean number of households visited (34.4) includes 20 permanent private households interviewed (58.1\%); 8.5 refusals (24.7\%); 3.3 permanent private households that were vacant $(9.6 \%)$; and 2.6 non-existent households or dwelling units that were no longer permanent private households (7.6\%).

Natural expansion factors in the design were based on the inverse probability of the selection of a household and the selection of an adult. Using the natural expansion factors, the age distribution showed the same pattern as the total population but an overestimation of the adult female population was found. Distribution by income quintiles showed a similar pattern to that described for the total population, despite of the slight underestimation in the wealthiest fifth. Further calibration of the natural expansion factors was necessary to obtain the census demographic structure of the Brazilian population [32].

The questionnaire originally proposed by the World Health Organization (WHO) was entirely reviewed and 
adapted to the Brazilian context. The following modules were included in the Brazilian WHS: socioeconomic status; self-rated health; risk factors; chronic diseases; coverage of health programs; responsiveness; and health expenditures, including private health insurance, health care services and products, diagnostics and laboratory tests, and medications.

For the statistical analysis, the sampling design was taken into account and all statistical analyses were conducted using SUDAAN [33].

Health services utilization was established by use of outpatient health care services in the 12 months prior to the interview.

Analysis of health status was based on the following question: "In general, how would you rate your health today"? Responses varied on a scale of 1 to $5(1=$ very bad; 2 = bad; 3 = fair; 4 = good; 5 = very good). The responses were aggregated to establish "good self-rated health" (good or very good), "fair" and "poor self-rated health (bad or very bad), which was used as an indicator of intensity of health care need.

To examine inequalities by socioeconomic status, two variables were considered: years of schooling and having private health insurance. Utilization of health services and self-rated health were jointly analyzed by educational level.

The $\chi^{2}$ statistical test was used to analyze the association between health services utilization and self-rated health.

The effects of the socioeconomic factors on health care utilization were analyzed by logistic regression models using years of schooling and private health insurance as independent variables, after controlling for age and sex.

Further multivariate analyses were conducted, considering self-rated health as an indicator of intensity of health care need. After controlling by age, effects of the socioeconomic variables (years of schooling and private health insurance) on health services utilization were analyzed according to health status (good, fair and poor) and sex.

\section{Results}

Of the 5000 respondents, $63.4 \%$ used an outpatient service in the year preceding the survey. As shown in Table 1 , higher percentages were found among women $(69.0 \%)$ when compared to men (56.9\%). The proportion of utilization varied with perception of health status, from $59.2 \%$, among those with good self-rated health, to $71.6 \%$, among those with poor health status. The association of outpatient services utilization and self-rated health was significant only for those of lower socioeconomic status, indicated by either one of the two variables. Overall, $28.4 \%$ with poor health status did not use outpatient services in the previous year, $25.9 \%$ among women and $32.4 \%$ among men, and had their needs unmet.

Figure 1 shows the proportions of health services utilization in the previous year and poor self-rated health by educational level. The social gradients are in opposite directions: although the less educated have the greatest proportion of poor self-rated health, they are the ones with smaller health care utilization.

The results of logistic regression presented in Table 2 show the effects of age and sex on outpatients services utilization in the previous year: higher rates are found

Table 1 Percentage of outpatient services utilization in the previous year according to self-rated health and educational level and private health insurance

\begin{tabular}{|c|c|c|c|c|c|c|}
\hline \multirow[t]{3}{*}{ Self-Rated Health } & \multicolumn{4}{|c|}{ Educational level } & \multirow{2}{*}{\multicolumn{2}{|c|}{ Total }} \\
\hline & \multicolumn{2}{|c|}{ Incomplete elementary school } & \multicolumn{2}{|c|}{ Complete elementary school and over } & & \\
\hline & $\mathrm{n}$ & $\%$ & $\mathrm{n}$ & $\%$ & $\mathbf{n}$ & $\%$ \\
\hline Good/Very good & 1135 & 51.8 & 1528 & 64.6 & 2663 & 59.2 \\
\hline Fair & 1257 & 66.2 & 615 & 70.2 & 1872 & 67.5 \\
\hline Bad/Very bad & 379 & 72.1 & 83 & 69.1 & 462 & 71.6 \\
\hline Total & 2771 & 61.1 & 2226 & 66.3 & 4997 & 63.4 \\
\hline p-value* & & & & & & \\
\hline \multirow[t]{3}{*}{ Self-Rated Health } & \multicolumn{4}{|c|}{ Private health insurance } & \multicolumn{2}{|c|}{ Total } \\
\hline & \multicolumn{2}{|c|}{ No } & \multicolumn{2}{|c|}{ Yes } & & \\
\hline & $\mathbf{n}$ & $\%$ & $\mathbf{n}$ & $\%$ & $\mathbf{n}$ & $\%$ \\
\hline Good/Very good & 1804 & 52.0 & 842 & 74.2 & 2647 & 59.1 \\
\hline Fair & 1483 & 65.7 & 381 & 74.4 & 1863 & 67.5 \\
\hline Bad/Very bad & 398 & 71.0 & 63 & 76.1 & 461 & 71.7 \\
\hline Total & 3685 & 59.6 & 1286 & 74.3 & 4971 & 63.4 \\
\hline$\overline{p \text {-value }}{ }^{*}$ & \multicolumn{2}{|c|}{$<0.001$} & \multicolumn{2}{|c|}{0.952} & \multicolumn{2}{|c|}{$<0.001$} \\
\hline
\end{tabular}

*Significance of the $\chi^{2}$ test of differences in proportions across categories of self-rated health status. 


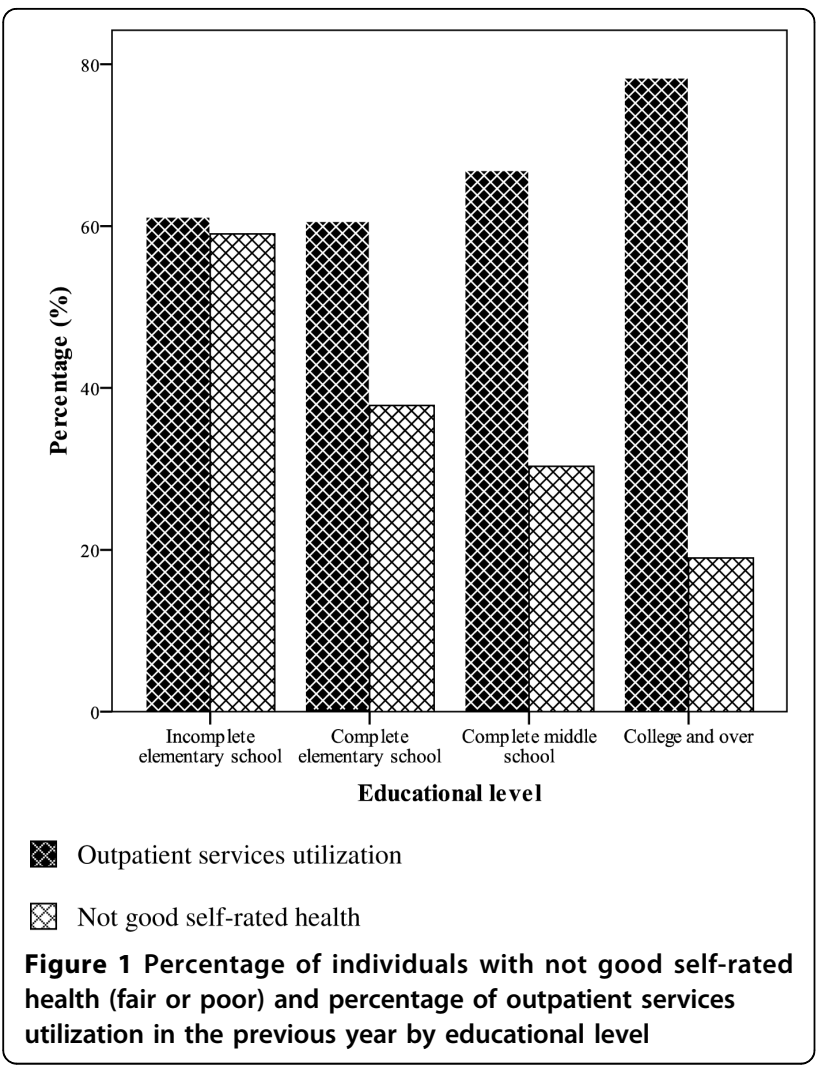

Table 2 Results of multivariate logistic analyses: effects of age, sex and socioeconomic variables on outpatient services utilization

\begin{tabular}{lccc}
\hline Model I & & & \\
\hline Independent variables & Exp(b)* & $\mathbf{C l}(\mathbf{9 5} \%)$ & p-value \\
\hline Age & 1.004 & $(1.000-1.008)$ & 0.039 \\
\hline Sex & 0.595 & $(0.519-0.682)$ & $<0.001$ \\
\hline Constant & 3.139 & $(2.396-4.111)$ & $<0.001$ \\
\hline Model II & & & \\
\hline Independent variables & Exp(b)* & $\mathbf{C l}(\mathbf{9 5} \%)$ & $\mathbf{p}$-value \\
\hline Age & 1.011 & $(1.006-1.015)$ & $<0.001$ \\
\hline Sex & 0.589 & $(0.513-0.676)$ & $<0.001$ \\
\hline Years of schooling & 1.056 & $(1.038-1.074)$ & $<0.001$ \\
\hline Constant & 1.730 & $(1.235-2.424)$ & 0.002 \\
\hline Model III & & & \\
\hline Independent variables & Exp(b)* & $\mathbf{C l}(\mathbf{9 5} \%)$ & $\mathbf{p}$-value \\
\hline Age & 1.003 & $(0.999-1.007)$ & 0.154 \\
\hline Sex & 0.585 & $(0.508-0.675)$ & $<0.001$ \\
\hline Private health insurance & 1.964 & $(1.653-2.333)$ & $<0.001$ \\
\hline Constant & 2.881 & $(2.190-3.789)$ & $<0.001$ \\
\hline
\end{tabular}

*Exponential of logistic regression estimated parameter. among women when compared to men ( $\mathrm{p}<0.001)$, and among the elderly when compared to the youngest ( $\mathrm{p}=$ 0.039). Moreover, a highly significant effect was found for years of schooling ( $\mathrm{p}<0.001)$, indicating a more frequent utilization of health services among more educated people, after controlling for the effects of age and sex. As to health insurance, the odds of utilization is almost two times greater $(\mathrm{OR}=1.964)$ among those holding a private health plan.

Models using health services utilization as the dependent variable and stratified by self-rated health (good, fair and poor) are shown in Table 3. Different effects of the independent variables on the utilization of outpatient services (after controlling by age and sex) are observed by strata. Among those with good health state perception, the effect of years of schooling was highly significant $(\mathrm{OR}=1.086 ; \mathrm{p}<0.001)$. Among those with fair evaluation of health state, the social gradient decreases yet statistically significant $(\mathrm{OR}=1.050 ; \mathrm{p}=$ 0.002). However, for those with poor health status, the effect of educational level disappears $(\mathrm{OR}=0.992)$.

Similar results were obtained using private health insurance as the independent variable (Table 4). The odds ratio decreases from 2.672 among those that reported good health to 1.290 among individuals with poor self-rated health and the effect was not statistically significant.

\section{Discussion}

Although health inequalities have most often been documented in wealthy countries, recent studies have made it evident that inequality in health and health care is also a prominent problem in developing countries [28,34-36]. In particular, analysis of the effect of health care is especially important in those countries, where resource limitations require that the effective use of all health interventions be made.

The results of the present study show the existence of significant socioeconomic inequalities in health services utilization. The rate of outpatient services utilization is higher among individuals who have private health insurance and higher level of education. Furthermore, the analysis shows social gradients in opposite directions: the less educated have the largest proportion of poor self-rated health but are the ones with lower utilization rate. Following the inverse care law [37], use of care varies inversely with the needs of the population served.

In Brazil, the association between utilization rate and socioeconomic status has been shown before [38,39], and is partly explained by the influence of private health plan coverage, since persons with private health insurance have shown higher odds of utilizing health care services [40]. Another factor is the limited capacity of public outpatient services to meet the demand of health care [41-43]. 
Table 3 Results of multivariate logistic analyses stratified by self-rated health status: effects of years of schooling on outpatient services utilization, after controlling for age and sex

\begin{tabular}{lccc}
\hline Good self-rated health $(\mathbf{n}=\mathbf{2 6 3 9})$ & & \\
\hline Independent variables & $\mathbf{E x p}(\mathbf{b})^{*}$ & $\mathbf{C l}(\mathbf{9 5} \%)$ & $\mathbf{p}$-value \\
\hline Age & 1.007 & $(1.000-1.013)$ & 0.042 \\
\hline Sex & 0.611 & $(0.507-0.737)$ & $<0.001$ \\
\hline Years of schooling & 1.086 & $(1.064-1.109)$ & $<0.001$ \\
\hline Constant & 1.256 & $(0.805-1.960)$ & 0.314 \\
\hline Fair self-rated health $(\boldsymbol{n}=1849)$ & & \\
\hline Independent variables & $\mathbf{E x p ( b )}$ & $\mathbf{C l}(\mathbf{9 5} \%)$ & $\mathbf{p}$-value \\
\hline Age & 1.008 & $(1.001-1.015)$ & 0.025 \\
\hline Sex & 0.615 & $(0.492-0.768)$ & $<0.001$ \\
\hline Years of schooling & 1.050 & $(1.018-1.083)$ & 0.002 \\
\hline Constant & 2.222 & $(1.321-3.737)$ & 0.003 \\
\hline Poor self-rated health $(n=459)$ & & \\
\hline Independent variables & $\mathbf{E x p}(\mathbf{b})^{*}$ & $\mathbf{C l}(95 \%)$ & $\mathbf{p}$-value \\
\hline Age & 0.996 & $(0.982-1.012)$ & 0.646 \\
\hline Sex & 0.720 & $(0.438-1.185)$ & 0.195 \\
\hline Years of schooling & 0.992 & $(0.925-1.064)$ & 0.822 \\
\hline Constant & 4.878 & $(1.741-13.670)$ & 0.003 \\
\hline
\end{tabular}

*Exponential of logistic regression estimated parameter.

Table 4 Results of multivariate logistic analyses stratified by self-rated health status: effects of private health insurance on outpatient services utilization after controlling for age and sex

\begin{tabular}{lccc}
\hline Good self-rated health $(\mathbf{n}=\mathbf{2 6 4 7})$ & & \\
\hline Independent variables & $\mathbf{E x p}(\mathbf{b})^{*}$ & $\mathbf{C l}(\mathbf{9 5} \%)$ & $\mathbf{p}$-value \\
\hline Age & 0.995 & $(0.989-1.001)$ & 0.112 \\
\hline Sex & 0.604 & $(0.499-0.730)$ & $<0.001$ \\
\hline Private health insurance & 2.672 & $(2.129-3.353)$ & $<0.001$ \\
\hline Constant & 2.803 & $(1.929-4.073)$ & $<0.001$ \\
\hline Fair self-rated health $(\mathrm{n}=1863)$ & & \\
\hline Independent variables & $\mathbf{E x p}(\mathbf{b})^{*}$ & $\mathbf{C l}(\mathbf{9 5} \%)$ & $\mathbf{p}$-value \\
\hline Age & 1.002 & $(0.995-1.008)$ & 0.588 \\
\hline Sex & 0.619 & $(0.494-0.775)$ & $<0.001$ \\
\hline Private health insurance & 1.521 & $(1.129-2.050)$ & 0.006 \\
\hline Constant & 3.484 & $(2.252-5.392)$ & $<0.001$ \\
\hline Poor self-rated health $(\mathrm{n}=461)$ & & \\
\hline Independent variables & $\mathbf{E x p ( b )}$ & $\mathbf{C l}(\mathbf{9 5} \%)$ & $\mathbf{p}$-value \\
\hline Age & 0.997 & $(0.985-1.010)$ & 0.662 \\
\hline Sex & 0.729 & $(0.442-1.203)$ & 0.215 \\
\hline Private health insurance & 1.290 & $(0.645-2.582)$ & 0.470 \\
\hline Constant & 4.416 & $(2.034-9.588)$ & $<0.001$ \\
\hline
\end{tabular}

*Exponential of logistic regression estimated parameter.
In relation to differences in health service utilization by sex, higher percentages of service utilization were found among women. Gender differences in health care utilization are well-known. In general, studies that address morbidity and health services utilization have found that women report more symptoms than men, have worse perception of health status, and are more likely to use medical care [44].

Our findings indicate a consistent association between the use of outpatient services and health care need, as individuals reporting poor health were more likely to use health care, corroborating results from other studies [45-47]. Yet, it is important to note that more than a quarter did not use an outpatient service in the preceding year despite reporting a fair or poor self-rated health, or having unmet health care needs. This issue deserves specific attention as studies have related unmet health care needs with an increase in mortality risk [48].

In regard to the association between socioeconomic status and health services utilization, according to selfrated health status, the analysis shows that the weaker the need, the sharper the socioeconomic gradient in health services utilization. The effects of both variables (private health insurance and years of schooling) are pronounced in the group with good self-rated health but decrease and are not significant among those with poor health status. While the wealthiest have high utilization rates regardless of self-perception of health problems, individuals of low socioeconomic status have to feel ill to seek health care.

In the group with good self-rated health, a possible explanation of the increased use among the richest is the higher use of preventive services. Differences in the main reason for seeking health care among rural and urban populations were evidenced in a previous study in Brazil: while use of preventive services was predominant in urban areas, presence of disease was the main reason in the rural population, which has lower socioeconomic status and more difficulties in the access of health services [49].

Unequal access to the services provided is another possible explanatory mechanism. Even though universal access to health services is guaranteed by the Brazilian constitution, which has allowed for improvements of many aspects in health $[50,51]$, some studies have shown inequality in the geographic distribution of available resources, mainly those requiring a more sophisticated technology for diagnosis [52,53].

The availability, the type and the quantity of services and resources (financial, human, and technological) are aspects of supply that may be influencing the pattern of utilization of health services in Brazil. A study using data from the National Household Sample Survey (2003) evidenced lower utilization by elderly rural residents when compared to old residents of urban areas, 
even among those who reported health problems. Furthermore, analysis showed that there was limited access to services with intermediate complexity [54].

An alternative explanation of the pro-rich inequality in health services utilization among those with good health status is that the wealthiest are more likely to use health services excessively, mainly among those that have a private health care plan. Our results show that the odds of outpatient services utilization is 2.7 greater among those with private health insurance than among those without private insurance. As has been pointed out by Starfield and collaborators [55], the excessive use of health services is becoming increasingly evident and deserves attention, as it is associated with higher costs, more medical procedures and more medications, without producing differences in quality of services [56]. In Brazil, excessive medical interventions during pregnancy and childbirth in the private sector may be influencing the increase in preterm deliveries, diminishing the gains resulting from improved antenatal care and increased newborn survival [57].

However, neither having private health insurance nor the availability of health services can ensure utilization of health services. Social, cultural and environment aspects are factors that could possibly influence health care use [58]. In Brazil, the lack of knowledge about disease prevention must also be considered, which particularly affects healthy habits, lifestyles and utilization of health care services [59,60].

On the other hand, the analysis evidenced that the effects of socioeconomic variables on health services utilization are reduced as the level of self-rated health status worsens, or as the health care need is more intense. Furthermore, among those with poor self-rated health, socioeconomic differences in health services utilization were not significant.

So, as compared to previous studies on inequalities in health care utilization [38-43], the present study shows encouraging news. The findings indicate that access and utilization of health services are provided to the population with perceived health problems regardless of educational level and are particularly relevant in the context of reducing socioeconomic health inequalities. Clearly, the evidence depicted here deserves further analysis, taking into account indicators of quality of care received.

Another limitation of this survey is that our measure of health services utilization is based on self-reported data. It is well known that such data are subject to measurement error that arises when respondents are asked to recall past utilization. So, the results here presented should be interpreted in the light of this limitation [61].

\section{Conclusions}

Our findings are important to the evaluation of the Brazilian health system performance. The evidence shows that the less educated use less frequently outpatient services, despite presenting worse health conditions, that is, health service utilization varies inversely with the needs of the population served.

However, socioeconomic inequalities in health services utilization decrease and even disappear in the most serious situations of need. Therefore, our results indicate a good performance of the Brazilian health system in narrowing socioeconomic inequalities in health, especially when the need is more intense. On the other hand, our results indicate the need to develop health promotion policies and to expand the health services supply in accordance with the territorial, cultural and social characteristics of the Brazilian population. Excessive use of medical services in the private health sector is another aspect that might be influencing the pattern of health services utilization and deserves further investigation.

\section{Authors' contributions}

CLS conceived and designed the article content, participated in the data analysis and drafting of the article, and coordinated the survey. PRBSJ was responsible for the data analysis and supervised the survey in some regions. GND participated in drafting the article and in the literature review. All authors read and approved the final manuscript.

\section{Competing interests}

The authors declare that they have no competing interests.

Received: 12 February 2010 Accepted: 23 July 2010

Published: 23 July 2010

\section{References}

1. Birch S, Gafni A: Achievements and challenges of medicare in Canada: Are we there yet? Are we on course? Int J Health Serv 2005, 35(3):443-63.

2. Marmot M, Ryff CD, Bumpass LL, Shipley M, Marks NF: Social inequalities in health: next questions and converging evidence. Soc Sci Med 1997, 44:901-10.

3. Macintyre S: The Black Report and beyond: what are the issues? Soc Sci Med 1997, 44:723-45, Review.

4. Schneider MC, Castillo-Salgado C, Loyola-Elizondo E, Bacallao J, Mujica OJ, Vidaurre M, Alleyne GA: Trends in infant mortality inequalities in the Americas: 1955-1995. J Epidemiol Community Health 2002, 56:538-41.

5. Adler N, Boyce WT, Chesney MA, Folkman S, Syme SL: Socioeconomic differences in health: No easy solution. J Am Med Assoc 1993, 269:3140-5.

6. Chandola T: Social class differences in mortality using the new UK National Statistics Socio-Economic Classification. Soc Sci Med 2000, 50:641-49.

7. Duncan GJ: Income dynamics and health. Int J Health Serv 1996, 26:419-44

8. Mackenbach JP, Kunst AE, Cavelaars AEJM, Gronhof F, Geurts JJM: Socioeconomic inequalities in morbidity and mortality in Western Europe. The EU Working Group on Socioeconomic Inequalities in Health. Lancet 1997, 349:1655-59.

9. Kaplan GA: People and places: Contrasting perspectives on the association between social class and health. Int J Health Serv 1996, 26:507-19.

10. Ram R: Income inequality, poverty, and population health: evidence from recent data for the United States. Health Serv Res 2003, 38(6 Pt 2):1905-21

11. Acheson D: Health inequalities impact assessment. Bull World Health Organ 2000, 78(1):75-85.

12. Foster $P$ : Inequalities in health: what health systems can and cannot do. BMJ 2005, 331(7521):855-6.

13. Exworthy $M$, Blane $D$, Marmot M: Tackling health inequalities in the United Kingdom: the progress and pitfalls of policy. Health Serv Res 2003, 38(6 Pt 2):1905-21 
14. Goddard M, Smith P: Equity of access to health care services: theory and evidence from the UK. Soc Sci Med 2001, 53(9):1149-62, Review.

15. Starfield B: Improving equity in health: a research agenda. Int J Health Serv 2001, 31(3):545-66.

16. Macinko J, Starfield B, Shi L: The contribution of primary care systems to health outcomes within Organization for Economic Cooperation and Development (OECD) countries, 1970-1998. Health Serv Res 2003, 38(3):831-65

17. Gepkens A, Gunning-Schepers LJ: Interventions to reduce socioeconomic health differences. Eur J Public Health 1996, 6:218-26.

18. Mackenbach JP, Stronks K: The development of a strategy for tackling health inequalities in the Netherlands. Int J Equity Health 2004, 3(1):11

19. Marmot MG: Tackling health inequalities since the Acheson inquiry. $J$ Epidemiol Community Health 2004, 58(4):262-3.

20. Oliver A, Mossialos E: Equity of access to health care: outlining the foundations for action. J Epidemiol Community Health 2004, 58(8):655-8

21. Parry J, Judge $K$ : Tackling the wider determinants of health disparities in England: a model for evaluating the New Deal for Communities regeneration initiative. Am J Public Health 2005, 95(4):626-8.

22. Mackenbach JP, Bakker MJ, European Network on Interventions and Policies to Reduce Inequalities in Health: Tackling socioeconomic inequalities in health: analysis of European experiences. Lancet 2003, 362(9393):1409-14.

23. Ostlin P, Braveman P, Dachs N: WHO Task Force on Research Priorities for Equity in Health, WHO Equity Team. Priorities for research to take forward the health equity policy agenda. Bull World Health Organ 2005, 83(12):948-53

24. Pappas G, Moss N: Health for All in the Twenty-First Century, World Health Organization renewal, and equity in health: a commentary. Int $J$ Health Serv 2001, 31(3):647-58.

25. Whitehead M: The concepts and principles of equity and health. Int J Health Serv 1992, 22(3):429-45.

26. Braveman P: Health disparities and health equity: concepts and measurement. Annu Rev Public Health 2006, 27:167-94.

27. Woodward A, Kawachi I: Why reduce health inequalities? J Epidemiol Community Health 2000, 54(12):923-29.

28. Braveman P, Tarimo E: Social inequalities in health within countries: not only an issue for affluent nations. Soc Sci Med 2002, 54(11):1621-35.

29. Feachem RGA: Poverty and inequality: a proper focus for the new century. Bull World Health Organ 2000, 78(1):1-2

30. PAHO (Panamerican Health Organization): Brazil. PAHO, Health in the Americas, 2002 Washington: PAHO 2002, 2:98-113.

31. Üstün TB, Chatterji S, Villanueva M, Çelik LBC, Sadana R, Valentine N, Ortiz J, Tandon A, Salomon J, Cao Y, Jun Xie Wan, Özaltin E, Mathers C, Murray CJL: WHO Multi-country Survey Study on Health and Responsiveness 20002001. Geneva: World Health Organization (GPE Discussion Paper 37) [http:// www3.who.int/whosis/discussion_papers/pdf/paper37.pdf], Accessed June 2006.

32. Vasconcellos MT, Silva PL, Szwarcwald CL: Sampling design for the World Health Survey in Brazil. Cad Saude Publica 2005, 21(Suppl):89-99.

33. Shah BV, Barnwell BG, Bieler GS: SUDAAN User's Manual. Release 7.5 Research Triangle Park, NC, USA: Research Triangle Institute 1997.

34. Szwarcwald CL, Souza-Júnior PR, Esteves MA, Damacena GN, Viacava F: Socio-demographic determinants of self-rated health in Brazil. Cad Saude Publica 2005, 21(Suppl):54-64.

35. Duncan BB, Rumel D, Zelmanowicz A, Mengue SS, dos Santos S, Dalmaz A: Social inequality in mortality in Sao Paulo State, Brazil. Int J Epidemiol 1995, 24(2):359-65

36. Victora CG, Vaughan JP, Barros FC, Silva AC, Tomasi E: Explaining trends in inequalities: evidence from Brazilian child health studies. Lancet 2000, 356:1093-98.

37. Hart JT: The inverse care law. Lancet 1971, 1(7696):405-12.

38. Travassos C, Viacava F, Pinheiro R, Brito A: Utilization of health care services in Brazil: gender, family characteristics, and social status. Rev Panam Salud Publica 2002, 11(5-6):365-73.

39. Pinheiro RS, Travassos C: Inequality in health care use by the elderly in three districts in Rio de Janeiro. Cad Saude Publica 1999, 15(3):487-96.

40. Viacava F, Souza-Júnior PRB, Szwarcwald CL: Coverage of the Brazilian population 18 years and older by private health plans: an analysis of data from the World Health Survey. Cad Saude Publica 2005, 21(Suppl1):119-128.
41. Castro MS, Travassos C, Carvalho MS: Impact of health services delivery on hospital admission utilization in Brazil. Rev Saude Publica 2005, 39(2):277-84

42. Oliveira EX, Travassos C, Carvalho MS: Access to hospitalization in Brazilian municipalities in 2000: territorial distribution in the Unified National Health System. Cad Saude Publica 2004, 20(Suppl 2):S298-309.

43. Brandt R: Private health care sector investment in Brazil: opportunities and obstacles. World Hosp Health Serv 2003, 39:11-4.

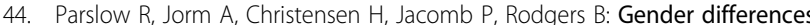
in factors affecting use of health services: an analysis of a community study of middle-aged and older Australians. Soc Sci Med 2004, 59(10):2121-9.

45. Suominen-Taipale AL, Koskinen S, Martelin T, Holmen J, Johnsen R: Differences in older adults' use of primary and specialist care services in two Nordic countries. Eur J Public Health 2004, 14(4):375-80.

46. Hakkinen $\mathrm{U}$ : Change in determinants of use of physician services in Finland between 1987 and 1996. Soc Sci Med 2002, 55(9):1523-37.

47. Lima-Costa MF, Barreto S, Giatti L, Uchoa E: Socioeconomic circumstances and health among the Brazilian elderly: a study using data from a National Household Survey. Cad Saude Publica 2003, 19(3):745-57.

48. Alonso J, Orfila F, Ruigómez A, Ferrer M, Antó JM: Unmet health care needs and mortality among Spanish elderly. Am J Public Health 1997, 87(3):365-70

49. Pinheiro RS, Viacava F, Travassos C, Brito AS: Gender, morbidity, access and utilization of health services in Brazil. Ciênc. Saúde Coletiva 2002, 7(4):684-707

50. Monteiro CA, Franca Junior I, Conde WL: Evolution of maternal and child health care in Sao Paulo (1984-1996). Rev Saude Publica 2000, 34(6 Suppl):19-25.

51. Victora CG, Bryce J, Fontaine O, Monasch R: Reducing deaths from diarrhoea through oral rehydration therapy. Bull World Health Organ 2000, 78(10):1246-55.

52. Souza-Junior PR, Szwarcwald CL, Barbosa Junior A, Carvalho MF, Castilho EA: HIV infection during pregnancy: the Sentinel Surveillance Project, Brazil, 2002. Rev Saude Publica 2004, 38:764-72.

53. Molina L, Dalben I, de Luca LA: An analysis of the opportunities of early detection of breast cancer. Rev Assoc Med Bras 2003, 49(2):185-90.

54. Travassos C, Viacava F: Access to and use of health services by rural elderly, Brazil, 1998 and 2003. Cad. Saúde Pública 2007, 23(10):2490-502.

55. Starfield B, Chang HY, Lemke KW, Weiner JP: Ambulatory specialist use by nonhospitalized patients in us health plans: correlates and consequences. J Ambul Care Manage 2009, 32(3):216-25.

56. Bereson RA: Getting serious about excessive Medicare spending: a purchasing model. Health Aff (Millwood) 2003, W3(Suppl Web Exclusives):586-602.

57. Barros FC, Victora CG, Barros AJ, Santos IS, Albernaz E, Matijasevich A, Domingues MR, Sclowitz IK, Hallal PC, Silveira MF, Vaughan JP: The challenge of reducing neonatal mortality in middle-income countries: findings from three Brazilian birth cohorts in 1982, 1993, and 2004. Lancet 2005, 365(9462):847-54.

58. Franks P, Gold MR, Clancy CM: Use of care and subsequent mortality: the importance of gender. Health Serv Res 1996, 31(3):347-63.

59. Leal MC, Gama SGN, Frias PG, Szwarcwald CL: Healthy lifestyles and access to periodic health exams among Brazilian women. Cad Saúde Pública 2005, 21(Suppl 1):78-88.

60. Monteiro CA, Moura EC, Conde WL, Popkin BM: Socioeconomic status and obesity in adult populations of developing countries: a review. Bull World Health Organ 2004, 82(12):940-6.

61. Sudman S, Bradburn NM: Effects of time and memory factors on response in surveys. Journal of the American Statistical Association 1973 68:805-15.

Pre-publication history

The pre-publication history for this paper can be accessed here: http://www.biomedcentral.com/1472-6963/10/217/prepub

doi:10.1186/1472-6963-10-217

Cite this article as: Szwarcwald et al: Socioeconomic inequalities in the use of outpatient services in Brazil according to health care need: evidence from the World Health Survey. BMC Health Services Research 2010 $10: 217$ 